\title{
ALFABETIZAÇÃO NO ENSINO FUNDAMENTAL DE NOVE ANOS: DESEMPENHO DE ALUNOS E SUAS IMPLICAÇÕES PARA AS PRÁTICAS PEDAGÓGICAS
}

\author{
Maria Regina GUARNIERI ${ }^{1}$ \\ Luciene Cerdas VIEIRA ${ }^{2}$
}

\begin{abstract}
RESUMO: Este trabalho focaliza dados oriundos de discussões realizadas com professoras que atuam nos três primeiros anos do ensino fundamental de nove anos, em duas escolas municipais do interior paulista, com o objetivo de diagnosticar a situação dos alunos em relação à alfabetização. A partir de avaliação aplicada em alunos que frequentam os três anos iniciais nessas escolas, o texto aborda os resultados do desempenho de 153 crianças do $3^{\circ}$ ano escolar na alfabetização. Relaciona também os dados dessa avaliação com aspectos que vêm caracterizando as práticas das professoras alfabetizadoras. Inicialmente, apresenta apontamentos sobre o processo de alfabetização no âmbito do ensino fundamental de nove anos e algumas implicações para as práticas das professoras. Em seguida, destaca os resultados da avaliação dos alunos dos $3^{\text {os }}$ anos, indicando capacidades já desenvolvidas por eles na alfabetização e outras a serem consolidadas. Os resultados indicam que essas crianças não se encontram alfabetizadas, revelando defasagens na apropriação de capacidades referentes à leitura e escrita, embora já estejam no $3^{\circ}$. ano escolar. Sugere ainda a necessidade das professoras reorganizarem suas práticas na sala aula e retomar o processo de alfabetização com os alunos, oportunizando a todos que se apropriem plenamente da leitura e da escrita.
\end{abstract}

PALAVRAS-CHAVE: Alfabetização. Ensino fundamental de nove anos. Práticas de professoras. Desempenho dos alunos.

\section{Introdução}

No contexto atual de reorganização do ensino fundamental de nove anos, apresentamos neste trabalho dados oriundos de discussões realizadas com professoras alfabetizadoras que atuam nos três primeiros anos desse nível de ensino, em duas escolas municipais do interior paulista, com a finalidade de diagnosticar a situação dos alunos em relação ao processo de alfabetização. A partir de avaliação aplicada nas turmas que frequentam os três anos iniciais das escolas investigadas, focalizamos nesse texto os dados referentes à avaliação de 153 crianças das turmas do $3^{\circ}$ ano do Ciclo Inicial de Alfabetização, com o objetivo de averiguar se esses alunos, que ingressaram aos seis anos na escola fundamental, se encontram alfabetizados, ou seja, lendo, escrevendo e produzindo textos com maior desenvoltura e autonomia.

\footnotetext{
${ }^{1}$ UNESP - Universidade Estadual Paulista. Faculdade de Filosofia e Ciências - Departamento de Didática. Araraquara - SP - Brasil. 14800-901 - mreginag@fclar.unesp.br

${ }^{2}$ Doutoranda em Educação Escolar. UNESP - Universidade Estadual Paulista. Faculdade de Filosofia e Ciências - Pós-Graduação em Educação Escolar. Araraquara - SP - Brasil. 14800-901 - lucerdasvieira@yahoo.com.br
} 
Os resultados dessa avaliação, que enfocou capacidades fundamentais do processo de alfabetização, foram cotejados com dados obtidos de manifestações das professoras alfabetizadoras dos três anos do ciclo inicial de ensino, sobre suas práticas, em encontros com as mesmas. Pretendemos identificar elementos que vêm caracterizando as práticas de professoras alfabetizadoras com a ampliação do tempo de escolarização e consequentemente do período destinado para alfabetizar.

Inicialmente, abordaremos alguns apontamentos sobre o processo de alfabetização no âmbito do ensino fundamental de nove anos e suas implicações para as práticas das professoras alfabetizadoras. Em seguida, nos reportamos aos resultados da avaliação feita com os alunos dos terceiros anos indicando tanto capacidades já desenvolvidas pelas crianças quanto outras a serem consolidadas no seu processo de alfabetização. Para finalizar, fazemos algumas considerações sobre as práticas das professoras alfabetizadoras, destacando aspectos que carecem de maior aprofundamento no período inicial de ensino e aprendizagem da leitura e escrita.

Nosso intuito é, portanto, contribuir para que o trabalho realizado nessas classes efetivamente se traduza na alfabetização das crianças, a fim de que elas possam seguir com maior autonomia as etapas seguintes do seu processo de escolarização.

\section{O ensino fundamental de nove anos: implicações para as práticas alfabetizadoras}

A implantação do Ensino Fundamental de Nove Anos, oficializada com a aprovação da Lei Federal N. 11.274 de fevereiro de 2006, tem por propósito garantir a todas as crianças tempo ampliado de convívio escolar com maiores oportunidades de aprendizagem. Nas orientações gerais para o ensino fundamental de nove anos (BRASIL, 2007), elaboradas pela SEB/MEC (Secretaria de Educação Básica/Ministério da Educação), um dos argumentos usados para a ampliação do período de escolarização obrigatória reside na constatação do ingresso tardio das crianças dos setores populares na escola ao se comparar que as crianças de seis anos de idade das classes sociais médias e altas já se encontram, majoritariamente, incorporadas ao sistema de ensino pré-escolar ou na primeira série do ensino fundamental. Portanto, pretende-se com o ensino de nove anos assegurar a um contingente maior de crianças, o ingresso mais cedo na escola obrigatória oportunizando sua permanência e a aprendizagem com qualidade. Visa também, diminuir os índices de fracasso escolar, sobretudo, na fase inicial de alfabetização. O envolvimento mais precoce das crianças dos meios menos favorecidos com a cultura escolar e com a língua escrita e seus usos, pode 
contribuir para a redução do fracasso na alfabetização (BATISTA, 2005), já que o sucesso ou fracasso do aluno nesse processo é determinante no percurso de sua vida escolar e no prosseguimento dos seus estudos.

Essa política prevê a universalização do direito à educação e a focalização na alfabetização como um processo de inclusão, um direito que deve ser avaliado em relação às práticas escolares de retenção que continuam a ocorrer muitas vezes de forma camuflada (FRADE, 2007). Consequentemente uma das repercussões do ensino de nove anos deve ser a antecipação em um ano ao direito de ser introduzido em práticas escolares, lato sensu, e em práticas escolares de alfabetização, stricto sensu, contribuindo efetivamente para que todos tenham acesso à leitura e à escrita e maiores chances de aprendizagem (DURAN, 2006; FRADE, 2007).

Para atender aos propósitos dessa medida educacional, impõe-se à escola fundamental outro ordenamento em sua estrutura compreendendo desde a adequação de espaços e tempos, dos materiais, até das formas de organização do trabalho pedagógico, o que implica conceber uma reorganização do currículo e, consequentemente, do ensino e da atuação docente para o atendimento dos alunos dessa faixa etária. Há que se definir, por exemplo, capacidades a serem abordadas e/ou consolidadas em cada ano escolar, estabelecendo pontos de partida e de chegada na organização do trabalho docente.

As pesquisas que focalizam o que ocorre no interior das escolas fundamentais configuradas em nove anos ainda são recentes, mas já apontam questões preocupantes como, por exemplo, ausência das condições já mencionadas, indefinição do que fazer com as classes de seis anos, ou seja, se o trabalho deve contemplar ou não a alfabetização das crianças, conduzindo as professoras a um conflito quanto à diferenciação do trabalho das turmas de $1^{\circ}$ ano ao das turmas de $1^{\mathrm{a}}$ série, ausência de diretrizes pedagógicas consistentes para orientar os professores, ênfase na sistematização do processo de escrita no primeiro ano escolar em detrimento de uma abordagem mais lúdica (BRUNETTI, 2007).

Estudos que analisam a implementação de políticas educacionais no Brasil desde as últimas décadas do século XX (BARRETO; MITRULIS, 1999; BARRETO; SOUZA, 2004; SAMPAIO; MARIN, 2004; MARIN; GIOVANNI; GUARNIERI, 2004) indicam que nem sempre essas medidas alcançam, na prática, resultados significativos na melhoria da qualidade do ensino e na aprendizagem dos alunos, ao mesmo tempo em que afetam profundamente o cotidiano do professor, alterando a organização do seu trabalho.

Os estudos relacionados às práticas de alfabetização, por exemplo, têm trazido resultados recorrentes sobre as dificuldades dos professores no desenvolvimento do trabalho 
de alfabetizar. Dentre tais resultados, se destacam: a falta clareza sobre o ponto de chegada dos alunos ao final do ano escolar, a perda da noção de terminalidade característica do sistema seriado, sendo que a noção de continuidade do processo que se confunde com a repetição do conteúdo no ano seguinte. Diante da necessidade de atender um grupo heterogêneo de crianças, revela-se entre outros aspectos a fragilidade da formação docente. Apesar do esforço e empenho dos alfabetizadores, a adoção dessas medidas não tem produzido os resultados esperados, inclusive antecipando o fracasso escolar (VIEIRA, 2007; GIOVANNI et al., 2004).

As dificuldades verificadas entre esses alfabetizadores na organização de suas práticas de ensino, tidas como consequência das orientações construtivistas para a alfabetização - que se tornaram hegemônicas no Brasil a partir dos anos de 1980 -, das políticas educacionais implementadas nas últimas décadas e da formação precária dos docentes, têm se “intensificado" ao longo dos anos, na medida em que se amplia o tempo da alfabetização, exigindo ainda a revisão e inovação de procedimentos didáticos. Nesse sentido, parece haver uma “[...] diluição ou preterição de metas e objetivos a serem atingidos gradativamente [...]" resultando “[...] em descompromisso com o desenvolvimento gradual e sistemático de habilidades, competências, conhecimentos.” (SOARES, 2003, p.4).

Focalizando a alfabetização das crianças, questionamos se o ingresso antecipado das crianças de seis anos no ensino fundamental tem contribuído para que se alcancem resultados mais satisfatórios na aquisição da leitura e da escrita.

\section{O desempenho dos alunos do terceiro ano escolar na alfabetização}

No contexto de reorganização das escolas para atender às exigências legais do ensino fundamental de nove anos, nosso trabalho aborda os resultados de uma avaliação realizada com 153 crianças do $3^{\circ}$ ano do Ciclo Inicial de Alfabetização - envolvendo duas escolas municipais do interior paulista - que teve como objetivo diagnosticar entre essas crianças a aquisição de capacidades fundamentais relacionadas ao processo de alfabetização, leitura e escrita.

Na elaboração dessa avaliação tomamos como principal referência o material do Centro de alfabetização, leitura e escrita (Ceale), Avaliação Diagnóstica da Alfabetização (BATISTA et al., 2005), que detalha capacidades a serem desenvolvidas durante os três anos do Ciclo Inicial de Alfabetização na configuração atual do ensino fundamental de nove anos. Em reuniões com o grupo de professoras alfabetizadoras dos três anos iniciais do ensino fundamental das duas escolas, foi possível conhecer um pouco do trabalho realizado por elas 
na alfabetização e das dificuldades que enfrentavam na sala de aula. Tivemos acesso também aos seus planejamentos, o que possibilitou melhor adequação das atividades propostas na avaliação, aos exercícios e tarefas trabalhadas em sala.

Das manifestações das professoras e análise de seus planejamentos emergiram alguns apontamentos sobre as práticas docentes nos anos iniciais de escolarização que sinalizam a ausência de certos elementos da competência para ensinar na sala de aula, conforme analisados por Guarnieri (1990), e que carecem de mais investigação. As professoras, de modo geral, revelam dificuldades em planejar suas aulas e estabelecer uma sequência clara de trabalho com a alfabetização, parecem não ter o hábito de corrigir as atividades dos alunos, nem oferecem a eles tarefas extra classe, usam muito pouco a lousa para escrever fazendo uso de atividades prontas, que trazem exercícios aos quais os alunos devem apenas completar ou preencher. Também manifestaram não ter clareza das capacidades a serem desenvolvidas na alfabetização e como sistematizá-las em atividades com objetivos claros.

Com base nos apontamentos desse processo, elaboramos uma avaliação para todas as turmas dos três anos do ciclo inicial de alfabetização enfocando algumas capacidades relacionadas à aquisição do sistema de escrita, à leitura e ao domínio da escrita e produção de textos (BATISTA et al., 2005), apresentadas no quadro abaixo:

\begin{tabular}{|l|}
\hline AQUISIÇÃO DO SISTEMA DE ESCRITA \\
\hline $\begin{array}{l}\text { C1 Compreender diferenças entre o sistema de escrita alfabético-ortográfico e outras formas gráficas e sistemas } \\
\text { de representação }\end{array}$ \\
\hline C2 Conhecer o alfabeto e os diferentes tipos de letras \\
\hline C3 Dominar convenções gráficas como orientação e alinhamento da escrita \\
\hline C4 Reconhecer palavras e unidades fonológicas ou segmentos sonoros como sílabas \\
\hline C5 Dominar a natureza alfabética do sistema de escrita \\
\hline C6 Dominar relações entre grafemas e fonemas \\
\hline LEITURA \\
\hline C7 ler e compreender palavras \\
\hline C8 ler e compreender frases \\
\hline C9 Compreender globalmente o sentido do texto \\
\hline DOMÍNIO DA ESCRITA E PRODUÇÃO DE TEXTOS \\
\hline C15 Escrever palavras com grafia desconhecida \\
\hline C 16 Escrever sentenças com pequena extensão \\
\hline
\end{tabular}

Quadro 1 - Capacidades avaliadas no Ciclo Inicial de Alfabetização.

Cabe esclarecer que, além dessas capacidades, consideramos também na avaliação dessas crianças, aspectos relacionados à coordenação motora na reprodução de símbolos 
(letras) e à orientação espacial (lateralidade, posição e distância), como requisitos para a alfabetização.

A avaliação foi composta de questões que envolviam: domínio do alfabeto no que tange ao reconhecimento e escrita das letras em seus diferentes tipos; sua sequenciação; distinção entre vogais e consoantes; identificação e contagem de letras e sílabas em palavras; formação de palavras; correspondência entre figuras, palavras e frases; leitura e compreensão de palavras, frases e textos curtos, e escrita de palavras e frases de pequena extensão. Foram, portanto, questões envolvendo capacidades fundamentais do processo inicial de alfabetização.

Priorizamos nesse texto a análise dos dados da avaliação de 153 alunos de sete turmas de $3^{\circ}$ ano do ensino fundamental de nove anos. Essa escolha deve-se ao fato de supor que essas crianças já desenvolveram algumas capacidades de leitura e escrita desde o primeiro ano na escola e estão nesse momento consolidando seu processo de alfabetização.

Na correção das provas do $3^{0}$ ano, que contemplou 39 questões, ao cotejarmos o total de acertos e erros obtidos pelos alunos na avaliação, identificamos três níveis de desempenho (Quadro 2) no que tange à apropriação das capacidades de leitura e escrita a serem desenvolvidas e consolidadas na passagem de um ano para o outro, sendo que no final do $3^{\circ}$. ano espera-se que estejam plenamente alfabetizados.

\begin{tabular}{|c|c|c|}
\hline Nível 1 & Nível 2 & Nível 3 \\
\hline $\begin{array}{l}\text { Os alunos se encontram num } \\
\text { estágio muito inicial em relação à } \\
\text { aprendizagem da escrita. Os alunos } \\
\text { compreendem as diferenças entre o } \\
\text { sistema de escrita e outras formas } \\
\text { gráficas de representação; } \\
\text { conhecem o alfabeto e diferentes } \\
\text { tipos de letras; dominam } \\
\text { convenções gráficas (orientação, } \\
\text { alinhamento, segmentação); } \\
\text { reconhecem unidades fonológicas } \\
\text { (rimas, sílabas). Neste nível estão, } \\
\text { portanto, começando a se } \\
\text { apropriar das habilidades } \\
\text { referentes ao domínio das regras } \\
\text { que orientam o uso do sistema } \\
\text { alfabético para ler e escrever. }\end{array}$ & $\begin{array}{l}\text { Além dos alunos já terem } \\
\text { consolidado as habilidades do nível } \\
\text { anterior, eles utilizam princípios } \\
\text { ortográficos nas relações } \\
\text { (regulares) } \\
\text { grafemas/fonemas; leem entre } \\
\text { compreendem palavras compostas } \\
\text { por sílabas } \\
\text { (consoante+vogal); canônicas } \\
\text { compreendem globalmente um } \\
\text { texto lido (pela professora), } \\
\text { identificando o assunto principal. } \\
\text { Neste nível, portanto, os alunos } \\
\text { começam a ser capazes de ler } \\
\text { palavras com vários tipos de } \\
\text { estrutura silábica. }\end{array}$ & $\begin{array}{l}\text { Além dos alunos já terem } \\
\text { consolidado as habilidades dos } \\
\text { níveis anteriores, eles são capazes } \\
\text { de ler e compreender frases com } \\
\text { estrutura simples; escrever, com } \\
\text { autonomia, palavras com grafia } \\
\text { desconhecida; e escrever sentenças } \\
\text { com pequena extensão. Neste } \\
\text { nível, portanto, os alunos } \\
\text { conseguem ler e escrever frases } \\
\text { com sintaxe simples } \\
\text { (sujeito+verbo+objeto) e ler } \\
\text { textos de curta extensão. }\end{array}$ \\
\hline
\end{tabular}

Quadro 2 - Níveis de desempenho dos alunos no processo de alfabetização.

Esperávamos nessa avaliação os alunos do $3^{\circ}$. ano não encontrassem dificuldades na sua realização, já que foram abordadas capacidades muito iniciais do processo de alfabetização. No entanto, embora existam diferenças e especificidades entre as turmas 
(conforme se verifica na Tabela 1), estando umas mais “avançadas” que outras no processo de alfabetização, os resultados foram aquém daqueles esperados.

Tabela 1 - Síntese de desempenho das turmas do $3^{\circ}$ Ano.

\begin{tabular}{l|l|c|c|c|c|c|c|l}
$\begin{array}{l}\text { Turma/ } \\
\text { Níveis }\end{array}$ & $\begin{array}{c}\text { Turma } \\
\mathbf{1}\end{array}$ & $\begin{array}{c}\text { Turma } \\
\mathbf{2}\end{array}$ & $\begin{array}{c}\text { Turma } \\
\mathbf{3}\end{array}$ & $\begin{array}{c}\text { Turma } \\
\mathbf{4}\end{array}$ & $\begin{array}{c}\text { Turma } \\
\mathbf{5}\end{array}$ & $\begin{array}{c}\text { Turma } \\
\mathbf{6}\end{array}$ & $\begin{array}{c}\text { Turma } \\
\mathbf{7}\end{array}$ & Total \\
\hline Nível 1 & 2 & 2 & 8 & 5 & 1 & 3 & 2 & $\mathbf{2 3}$ \\
\hline Nível 2 & 13 & 4 & 4 & 4 & 11 & 5 & 10 & $\mathbf{5 1}$ \\
\hline Nível 3 & 14 & 10 & 5 & 7 & 13 & 16 & 14 & $\mathbf{7 9}$ \\
\hline Total & $\mathbf{2 9}$ & $\mathbf{1 6}$ & $\mathbf{1 7}$ & $\mathbf{1 6}$ & $\mathbf{2 5}$ & $\mathbf{2 4}$ & $\mathbf{2 6}$ & $\mathbf{1 5 3}$
\end{tabular}

Verificamos que dos 153 alunos avaliados no $3^{\circ}$. ano, 79 estão no nível 3, ou seja, demonstraram ser capazes de ler e escrever, embora com dificuldades, frase com sintaxe simples e texto de curta extensão. No nível 2 estão 51 alunos que começam a ler palavras com diferentes tipos de estrutura silábica. No nível 1 encontram-se 23 alunos que começam a se apropriar das habilidades referentes ao domínio das regras que orientam o uso do sistema alfabético para ler e escrever, estando num patamar muito inicial da aprendizagem da leitura e escrita.

Se considerarmos, no entanto, o total de alunos nos níveis 1 e 2, verificamos que 74 crianças do $3^{\circ}$ ano, isto é, quase a metade das crianças no final do ciclo de alfabetização, apresentam defasagens na apropriação das capacidades essenciais da aprendizagem da leitura e escrita. Esses alunos de modo geral não consolidaram aspectos como: a diferenciação entre o sistema de escrita e outras formas de representação; o domínio do alfabeto e dos diferentes tipos de letras; a utilização de convenções gráficas (alinhamento, segmentação e direcionamento); o reconhecimento de unidades fonológicas (sílabas e letras); e o domínio da natureza alfabética da escrita e das relações entre grafemas e fonemas.

Ressaltamos também que nas atividades que envolviam a escrita de palavras conhecidas ou com grafia desconhecida, mesmo os alunos que tiveram um melhor desempenho na avaliação apresentaram palavras grafadas com omissões, acréscimos ou troca de sílabas ou de letras em sílabas. O mesmo aconteceu na escrita de uma frase de pequena extensão, na qual se verifica muitas vezes ausência de segmentação correta entre as palavras, e total desconhecimento do uso de inicial maiúscula em parágrafos e de pontuação no final de frase. 
Considerando que esses alunos devem estar plenamente alfabetizados até o final do $3^{\circ}$. ano, lendo e escrevendo com fluência, rapidez e autonomia, notamos que mesmo aqueles com melhor nível de desempenho na avaliação estão aquém dessa meta.

Diante desses dados, acreditamos que é necessário às professoras reorganizar suas práticas, retomando o processo de alfabetização, por meio de um trabalho sistemático que privilegie a consolidação de capacidades fundamentais na aprendizagem da leitura e escrita, sem as quais os alunos certamente terão muitas dificuldades no andamento do seu processo de escolarização. Assim, as atividades realizadas em sala devem privilegiar: a diferenciação entre o sistema de escrita alfabético-ortográfico de outras formas gráficas e sistemas de representação; o domínio do alfabeto e dos diferentes tipos de letras; o domínio de convenções gráficas (alinhamento, segmentação e direcionamento); o reconhecimento de unidades fonológicas (sílabas e letras); o domínio da natureza alfabética do sistema de escrita; e o domínio das relações entre grafemas e fonemas.

Avançando no processo de alfabetização, as professoras devem propor a sistematização da leitura, compreensão e escrita de frases e textos curtos, enfatizando também o conhecimento e a utilização de elementos convencionais de organização de textos, tais como segmentação entre palavras, uso de parágrafos, de inicial maiúscula em parágrafos e de pontuação e marcas de oralidade.

\section{Algumas considerações}

Diante da reorganização do ensino fundamental para nove anos, nos parece que a ampliação do tempo de escolarização não vem contribuindo significativamente para garantir a todos o acesso à leitura e à escrita e diminuir o fracasso desses alunos na alfabetização. Os dados de nossa pesquisa confirmam que a ampliação do tempo de escolarização deve estar atrelada à qualidade do ensino oferecido e a oportunidades efetivas de aprendizagem da leitura e escrita, destacando-se o trabalho sistemático com capacidades fundamentais da alfabetização, com objetivos bem definidos a serem alcançados em cada ano do Ciclo Inicial de Alfabetização.

Segundo Soares (2003), a divulgação das orientações construtivistas para a alfabetização gerou, muitas vezes, uma concepção holística de que as relações fonemagrafema não devam ser objeto de ensino direto e explícito, pois sua aprendizagem decorreria de forma natural na interação com a língua escrita. Nesse sentido, concordamos com a autora sobre a necessidade de se retomar capacidades específicas para o trabalho com a 
alfabetização. Embora o tempo para alcançar a plenitude desse processo tenha se estendido com a implementação do ensino fundamental de nove anos, os alunos avaliados ainda encontram-se num estágio muito inicial da alfabetização.

Os resultados da avaliação diagnóstica sugerem pontos de partida para a reorganização e continuidade do trabalho das professoras, haja vista a necessidade de se retomar algumas capacidades que precisam ainda ser consolidadas pelos alunos, e de se introduzir outras a serem trabalhadas sistematicamente com o objetivo de que todos os alunos se alfabetizem.

Constatamos pelos dados deste estudo indícios de que elementos do processo de ensino e muitos saberes da prática docente vêm se perdendo, com sérios prejuízos a aprendizagem dos alunos. As professoras das turmas avaliadas encontram muita dificuldade em organizar a alfabetização na perspectiva construtivista e planejar suas aulas estabelecendo um trabalho sequenciado que consista na introdução, retomada e consolidação de capacidades e conhecimentos fundamentais para a aprendizagem da leitura e escrita. O que sem dúvida, aponta evidências sobre a necessidade de efetivos investimentos na formação dos docentes, repensando suas competências e saberes, e de apoio às escolas no processo de reorganização de suas práticas tendo em vista a qualidade do ensino.

\section{LITERACY IN NINE-YEAR ELEMENTARY SCHOOL: STUDENTS' PERFORMANCE AND ITS IMPLICATIONS TO PEDAGOGIC PRACTICES}

ABSTRACT: This paper focuses data from discussions done with teachers who work with three early years of nine-year elementary school, in two Municipal schools of São Paulo inland, in order to investigate the students' literacy degree. Considering a test applied to students of three early years of those schools, this study deals with the literacy performance results of 153 children of third school year. It also relates data of this test with some aspects that have characterized the literacy teachers' practices. Initially, it presents any considerations on the literacy process in extent of nine-year elementary school and some implications for the teachers' practices. Then, it emphasizes the test results of third year students, pointing out what skills were already developed by them in literacy process and what skills must be improved. Results show that those children are not literated. They demonstrate difficulties in the appropriation of reading and writing skills, even in the third school year. It suggests the teachers' need to reorganize their practices in classroom and to revise students' literacy process, allowing to every student the full appropriation of reading and writing.

KEYWORDS: Literacy. Nine-year elementary school. Teachers' practices. Students' performance. 


\section{REFERÊNCIAS}

BARRETO, E. S. de S.; SOUZA, S. Z. Ciclos: estudos sobre as políticas implementadas no Brasil. In: REUNIÃO ANUAL DA ANPED, 27., 2004, Caxambu. Anais... Caxambu:

ANPED, 2004. Disponível em <http://www.anped.org.br/27/diversos/te_elba_barretto.pdf > . Acesso em: 09 mar. 2006.

BARRETO, E. S. de S.; MITRULIS, E. Os ciclos escolares: elementos de uma trajetória. In: Cadernos de Pesquisa, São Paulo, n.108, p.24-48, nov. 1999.

BATISTA, A. A. G. Organização da alfabetização no ensino fundamental de 9 anos. Belo Horizonte: Ceale, 2005. (Coleção Instrumentos da Alfabetização, 1).

BATISTA, A. A. G. et al. Avaliação diagnóstica da alfabetização. Belo Horizonte: Ceale, 2005. (Coleção Instrumentos da Alfabetização, 3).

BRASIL. Ministério da Educação. Secretaria de Educação Básica. Departamento de Educação Infantil e Ensino Fundamental. Ensino fundamental de nove anos: orientações para a inclusão da criança de seis anos de idade. 2.ed. Brasília: FNDE, 2007.

BRUNETTI, G. C. O trabalho docente face ao atendimento da faixa etária de 6 anos no ensino fundamental: um estudo a partir das manifestações de um grupo de professoras alfabetizadoras no município de Araraquara. 2007. 170f. Dissertação (Mestrado em Educação Escolar) - Faculdade de Ciências e Letras, Universidade Estadual Paulista, Araraquara, 2007.

DURAN, M. C. G. Ensino Fundamental de nove anos: argumentando sobre alguns dos seus sentidos. In: SILVA, A. M. M. et al. Políticas Educacionais, tecnologias e formação do educador: repercussões sobre a didática e as práticas de ensino. Recife: ENDIPE, 2006. p.337-349.

FRADE, I. C. A. da S. A alfabetização na escola de nove anos: desafios e rumos. In: SILVA, E. T. da. (Org.). Alfabetização no Brasil: questões e provocações da atualidade. Campinas: Autores Associados, 2007. p.73-112.

GIOVANNI, L. M. et al. Significado das séries escolares e a implementação de ciclos na escola fundamental. In: COLÓQUIO SOBRE QUESTÕES CURRICULARES, 6.; COLÓQUIO LUSO-BRASILEIRO SOBRE QUESTÕES CURRICULARES: CURRÍCULO, PENSAR, INVENTAR, DIFERIR, 2., 2004, Rio de Janeiro; Porto. Anais... Rio de Janeiro: UERJ, 2004. 1 CD-ROM.

GUARNIERI, M. R. O trabalho docente nas séries iniciais de $\mathbf{1}^{\mathbf{0}}$ grau: elementos para a compreensão da competência no cotidiano escolar. 1990. 229f. Dissertação (Mestrado em Educação) - Centro de Educação e Ciências Humanas, Universidade Federal de São Carlos, São Carlos, 1990. 
MARIN, A. J.; GIOVANNI, L. M.; GUARNIERI, M. R. Formação e ação docentes: tempos sombrios os que se delineiam para o futuro. In: ROMANOWSKI, J. P.; MARTINS, P. L.; JUNQUEIRA, S. A. Conhecimento local e conhecimento universal. Práticas sociais: aulas, saberes e políticas. Curitiba: Champagnat, 2004. v.1, p.171-182.

SAMPAIO, M. das M. F.; MARIN, A. J. Precarização do trabalho docente e seus efeitos sobre as práticas curriculares. Educação e Sociedade, São Paulo, v.25, n.89, p.1203-1225, dez. 2004.

SOARES, M. Letramento e alfabetização: as muitas facetas. In: REUNIÃO ANUAL DA ANPED, 26., 2003, Caxambu. Anais... Caxambu: ANPED, 2003. Disponível em <http://www.anped.org.br/26/outrostextos/semagdasoares.doc>. Acesso em: 14 fev. 2004.

VIEIRA, L. C. As práticas das professoras alfabetizadoras como objeto de investigação: teses e dissertações de programas de pós-graduação do Estado de São Paulo (1980 a 2005). 2007. 152f. Dissertação (Mestrado em Educação Escolar) - Faculdade de Ciências e Letras, Universidade Estadual Paulista, Araraquara, 2007. 